\title{
ANALISIS HAK KEPEMILIKAN LAHAN PERKEBUNAN KELAPA SAWIT DI DESA SETABU DAN DESA LIANG BUNYU KECAMATAN SEBATIK BARAT KABUPATEN NUNUKAN
}

\author{
Deby Ayu Herlin ${ }^{1}$, Adi Sutrisno ${ }^{2}$ \\ ${ }^{1,2}$ Universitas Borneo Tarakan, Fakultas Pertanian, Program Studi Agribisnis, Jl. Amal Lama no 1, Tarakan \\ Timur, Tarakan. \\ Email: debyayuherlin1995@gmail.com
}

Received: 1 Maret 2018

Accepted: 20 April 2019

\begin{abstract}
While the research objectives formulated based on the background are: (1) to know the ownership rights of plantation land based on legislation in laws in the Republic of Indonesia; (2) to know the facts of land ownership rights of oil palm plantations in Setabu Village and Liang Bunyu Village, West Sebatik District, Nunukan Regency; and (3) to know the suitability of the land ownership rights stated in the laws and regulations with the ownership facts in Setabu and Liang Bunyu Villages in West Sebatik District, Nunukan Regency. The data used consists of secondary data and primary data, collected using document study techniques and interviews using questionnaires. The data obtained are then analyzed using qualitative content analysis techniques and qualitative descriptive analysis. The results of this study are (1) plantation land ownership rights based on laws and regulations consisting of ownership rights, use rights, business use rights and customary rights, where ownership rights are the most fulfilled and strongest rights: (2) plantation land rights over land controlled by farmers in Setabu Village and Liang Bunyu Village are "Right of Ownership" with proof of title in the form of Certificate, Letter of Village Head (SPPT) and Sub-District Letter (SPPH); and (3) the plantation ownership rights included in the legislation and the ownership rights to the plantation land controlled by the farmers of Setabu Village and Liang Bunyu Village are in conformity, namely the ownership of plantation land in the form of " Ownership Rights ", but evidence of plantation ownership rights in the two villages are more in the form of a Village Head Letter (SPPT) and Sub-District Letter (SPPH).
\end{abstract}

Keywords: Property rights, legislation

ABSTRAK

Sedangkan tujuan penelitian yang dirumuskan berdasarkan latar belakang adalah: (1) untuk mengetahui hak kepemilikan lahan perkebunan berdasarkan peraturan perundang-undangan di Republik Indonesia; (2) untuk mengetahui fakta hak kepemilikan lahan perkebunan kelapa sawit di Desa Setabu dan Desa Liang Bunyu, Kecamatan Sebatik Barat, Kabupaten Nunukan; dan (3) untuk mengetahui kesesuaian hak kepemilikan tanah yang dinyatakan dalam undang-undang dan peraturan dengan fakta kepemilikan di Desa Setabu dan Liang Bunyu di Kecamatan Sebatik Barat, Kabupaten Nunukan. Data yang digunakan terdiri dari data sekunder dan data primer, dikumpulkan menggunakan teknik studi dokumen dan wawancara menggunakan kuesioner. Data yang diperoleh kemudian dianalisis dengan menggunakan teknik analisis isi kualitatif dan analisis deskriptif kualitatif. Hasil dari penelitian ini adalah (1) hak kepemilikan tanah perkebunan berdasarkan hukum dan peraturan yang terdiri dari hak kepemilikan, hak pakai, hak pakai bisnis dan hak ulayat, di mana hak kepemilikan adalah hak yang paling terpenuhi dan terkuat: (2) hak atas tanah perkebunan atas tanah yang dikuasai oleh petani di Desa Setabu dan Desa Liang Bunyu adalah "Hak Kepemilikan" dengan bukti kepemilikan dalam bentuk Sertifikat, Surat Kepala Desa (SPPT) dan Surat Kecamatan (SPPH); dan (3) hak kepemilikan perkebunan yang termasuk dalam undang-undang dan hak kepemilikan atas tanah perkebunan yang dikendalikan oleh petani Desa Setabu dan Desa Liang Bunyu sudah sesuai, yaitu kepemilikan tanah perkebunan dalam bentuk "Hak Kepemilikan", namun bukti hak kepemilikan perkebunan di kedua desa tersebut lebih berupa Surat Kepala Desa (SPPT) dan Surat Camat (SPPH).

Kata kunci: Hak properti, undang-undang

\section{PENDAHULUAN}

Hak milik adalah hak turun-temurun terkuat dan terpenuh yang dapat dipunyai orang atas tanah, dengan mengingat ketentuan dalam pasal 6 yang berbunyi Semua hak atas tanah mempunyai fungsi sosial Hak milik dapat beralih dan dialihkan kepada pihak lain. Berdasarkan Undang-Undang No. 5 Tahun 1960 Tentang Peraturan Dasar Pokok-Pokok Agraria Presiden Republik Indonesia 
Perkebunan adalah segala kegiatan pengelolaan sumber daya alam, sumber daya manusia, sarana produksi, alat dan mesin, budi daya, panen, pengolahan, dan pemasaran terkait Tanaman Perkebunan, Berdasarkan Pasal 1 ayat 1 Undang - undang Perkebunan.

Kecamatan Sebatik Barat terdapat 4 Desa yaitu Desa Setabu, Desa Binalawan, Desa Liang Bunyu, Desa Bambangan. Alasan peneliti hanya meilih Desa Setabu dan Desa Liang Bunyu karena jarak dari tempat tinggal terjangkau dari peneliti dan petani sawit yang berada di Desa Setabu dan Desa Liang Bunyu Desa yang banyak petani sawitnya. Jumlah petani sawit di Desa setabu sejumlah 362 dan Desa Liang Bunyu sejumlah 304. Di Kecamatan Sebatik Barat terdapat masyarakat yang memiliki perkebunan kelapa sawit, berdasarkan penjelasan di atas mengenai hak pemilikan lahan dan masyarakat pemilik kebun kelapa sawit di Kecamatan Sebatik Barat. Permasalahan yang ada di Sebatik Barat khususnya di Desa Setabu dan Desa Liang Bunyu yaitu masalah mengenai lahan hutan lindung, selanjutnya permasalahan yang sering terjadi di Desa Setabu dan Liang Bunyu yaitu selisih paham oleh para petani karena lahan yang mereka garap terkadang berubah patokan lahannya. Hak kepemiikan lahan perkebunan kelapa sawit umumnya lahan yang diusahakan oleh masyarakat adalah lahan eks hutan dan apabila hutan tersebut adalah hutan lindung maka petani kelapa sawit tidak dapat memperoleh hak milik. Maka peneliti ingin menjawab permasalahan mengenai hak kepemilikan lahan perkebunan kelapa sawit di Desa Setabu dan Desa Liang Bunyu Kecamatan Sebatik Barat Kabupaten Nunukan.

\section{METODE PENELITIAN \\ Lokasi Dan Waktu Penelitian}

Penentuan metode lokasi penelitian dengan menggunakan accidental sampling yaitu di Desa Setabu dan Desa Liang Bunyu Kecamatan Sebatik Barat Kabupaten Nunukan.

\section{Metode Penentuan Sampel}

Populasi dalam penelitian ini adalah yang menjadi sumber data dalam penelitian ini adalah masyarakat yang memiliki kebun kelapa sawit di Kecamatan Sebatik Barat. Dalam penelitian ini responden di tentukan dengan accidental sampling, Sampel yang di ambil sebanyak 100 responden dari jumlah Respoden di Desa Setabu sejumlah 362 dan Desa Liang Bunyu sejumlah 304, masing - masing Desa diambil 50 dari Desa Setabu dan 50 dari Desa Liang Bunyu. Jumlah
Informan kunci dalam dalam penelitian ini adalah 2 informan kunci (key Informan) dari 2 Desa 1 Kecamatan dimana informan kuncinya adalah Kepala Desa dan Sekertaris Desa Setabu dan Liang Bunyu.

\section{Analisis Data}

1.Analisis isi kualitatif, Analisis isi kualitatif digunakan untuk menganalisis data sekunder yang bersumbar dari peraturan perundangan dan dokumen kebijakan, khususnya peraturan perundangan dan kebijakan yang berkenaan dengan Hak Kepemilikan Lahan.

2.Deskriptif kualitatif, dilakukan dengan metode interaktif.

\section{HASIL DAN PEMBAHASAN \\ Deskripsi Daerah Penelitian}

Sebagai wilayah perbatasan yang saat ini menjadi perhatian pemerintah untuk dikembangkan, maka pada tahun 2011 Pulau Sebatik kembali dimekarkan dari 2 (dua) kecamatan menjadi 5 (lima) kecamatan yang ditandai dengan dibentuknya Kecamatan Sebatik Tengah, Sebatik Utara dan Sebatik Timur. Pemekaran ini ditandai dengan disahkannya Peraturan Daerah Nomor 25 Tahun 2011 tentang Pembentukan Kecamatan Sebatik Timur, Sebatik Utara dan Sebatik Tengah di Lingkungan Pemerintah Kabupaten Nunukan pada tanggal 10 Agustus 2011 yang ditindaklanjuti dengan pengisian Struktur Pemerintahan Kecamatan pada pelantikan tanggal 27 Oktober 2011 berdasarkan Keputusan Bupati Nunukan.

\section{Karakteristik Responden \\ Karakteristik Responden Berdasarkan Tingkat Umur \\ Berdasarkan tabel 1.dapat diketahui bahwa} jumlah responden petani di Desa Setabu sebanyak 50 orang, berdasarkan tingkat usia maka didapatkan data bahwa pada umumnya yaitu sebesar $40 \%$ responden petani memiliki usia berkisar 54-61 tahun, adapun sisanya yaitu $8 \%$ responden petani memiliki usia berkisar 3037 tahun, 20\% responden petani memiliki usia berkisar antara $38-45$ tahun, dan $32 \%$ responden petani memiliki usia berkisar 46 -53 tahun.

Tabel 1. Klasifikasi Responden Berdasarkan usia di Desa Setabu 
Sumber:Data primer yang di olah (2018)

Tabel 2. Klasifikasi Responden Berdasarkan usia di Desa Liang Bunyu

\begin{tabular}{cccc}
\hline No & $\begin{array}{c}\text { Komposisi } \\
\text { umur }\end{array}$ & $\begin{array}{c}\text { Jumlah } \\
\text { orang }\end{array}$ & $\begin{array}{c}\text { Prosentase } \\
(\%)\end{array}$ \\
\hline 1 & $32-40$ & 12 & $24 \%$ \\
2 & $41-49$ & 13 & $26 \%$ \\
3 & $50-58$ & 13 & $26 \%$ \\
4 & $59-67$ & 12 & $24 \%$ \\
\hline & Jumlah & 50 & $100 \%$ \\
\hline
\end{tabular}

Sumber:Data primer yang di olah (2018)

Sedangkan berdasarkan tabel 2. dapat diketahui bahwa jumlah responden petani di Desa Liang Bunyu sebanyak 50 orang, berdasarkan tingkat usia maka didapatkan data bahwa pada umumnya yaitu sebesar $26 \%$ responden petani memiliki usia berkisar 41-49 tahun dan 50-51 tahun.

\section{Karakteristik Responden Berdasarkan}

\section{Tingkat Pendidikan.}

Berdasarkan tabel 3. dapat diketahui bahwa jumlah responden petani di Desa Setabu sebanyak 50 orang, berdasarkan tingkat pendidikan petani maka didapatkan data bahwa pada umumnya yaitu sebesar $48 \%$ petani memiliki tingkat pendidikan SD dengan jumlah 34 orang, responden dengan persentase 5,2\% berada pada tingkat pendidikan Sarjana dengan jumlah 10 orang.

Tabel 3. Klasifikasi Responden Berdasarkan Pendidikan di Desa Setabu

\begin{tabular}{cccc}
\hline No & $\begin{array}{c}\text { Tingkat } \\
\text { pendidikan }\end{array}$ & $\begin{array}{c}\text { Jumlah } \\
\text { Orang }\end{array}$ & $\begin{array}{c}\text { Prosentase } \\
(\mathbf{\%})\end{array}$ \\
\hline 1 & SD & 24 & $48 \%$ \\
2 & SMP & 17 & $34 \%$ \\
3 & SMA & 7 & $14 \%$ \\
4 & S1 & 2 & $4 \%$ \\
\hline & Jumlah & 50 & $100 \%$ \\
\hline
\end{tabular}

Sumber: Data primer yang di olah (2018)

Tabel 4. Klasifikasi Responden Berdasarkan Pendidikan di Desa Liang Bunyu

\begin{tabular}{cccc}
\hline No & $\begin{array}{c}\text { Tingkat } \\
\text { pendidikan }\end{array}$ & $\begin{array}{c}\text { Jumlah } \\
\text { Orang }\end{array}$ & $\begin{array}{c}\text { Prosentase } \\
(\%)\end{array}$ \\
\hline 1 & SD & 19 & $38 \%$ \\
2 & SMP & 15 & $30 \%$ \\
3 & SMA & 14 & $28 \%$ \\
4 & S1 & 2 & $4 \%$ \\
\hline & Jumlah & 50 & $100 \%$ \\
\hline
\end{tabular}

Sumber: Data primer yang di olah (2018)

Berdasarkan tabel 4. dapat diketahui bahwa jumlah responden petani di Desa Liang Bunyu sebanyak 50 orang, berdasarkan tingkat pendidikan petani maka didapatkan data bahwa

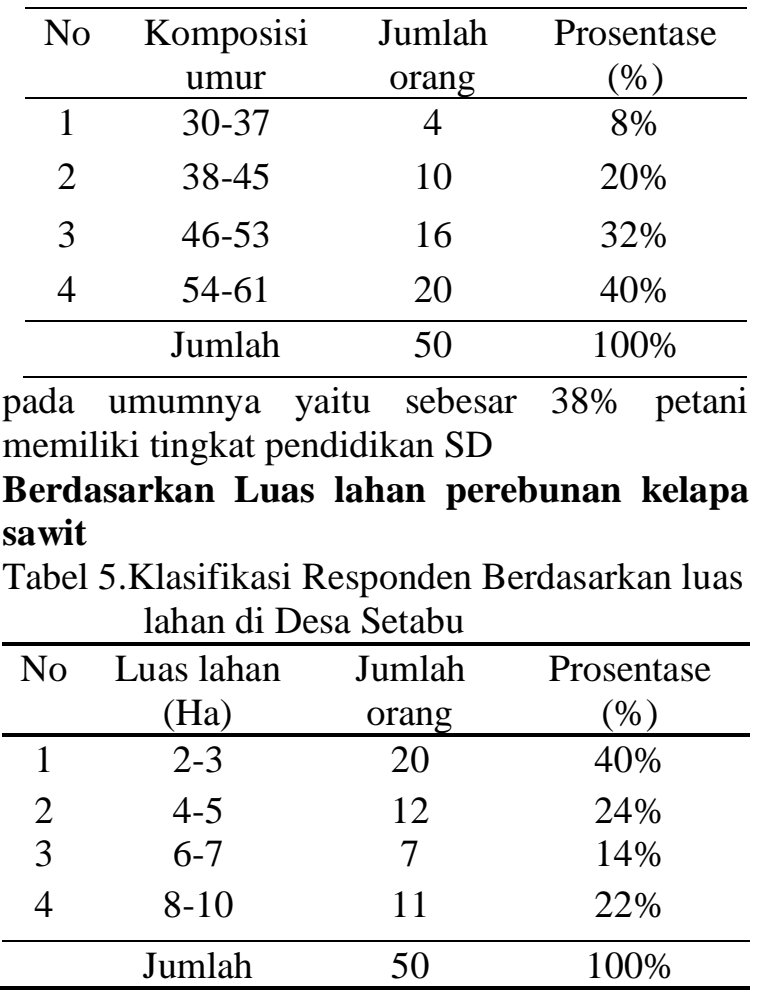

Berdasarkan tabel 5. dapat diambil kesimpulan bahwa pada umumnya $40 \%$ petani Desa Setabu Kecamatan Sebatik Barat Kabupaten Nunukan memiliki luas lahan 2-3 ha, 24\% petani memiliki luas lahan 4-5 ha, $14 \%$ petani memiliki luas lahan 6-7 ha dan $22 \%$ petani yang memiliki luas lahan 8-10 ha.

Tabel 6. Klasifikasi Responden Berdasarkan luas lahan di Desa Liang Bunyu

\begin{tabular}{cccc}
\hline No & $\begin{array}{c}\text { Luas } \\
\text { lahan (Ha) }\end{array}$ & $\begin{array}{c}\text { Jumlah } \\
\text { orang }\end{array}$ & $\begin{array}{c}\text { Prosentase } \\
(\%)\end{array}$ \\
\hline 1 & $2-4$ & 30 & $60 \%$ \\
2 & $5-7$ & 9 & $18 \%$ \\
3 & $8-10$ & 7 & $14 \%$ \\
4 & $11-12$ & 4 & $8 \%$ \\
\hline & Jumlah & 50 & $100 \%$ \\
\hline
\end{tabular}

Sumber: Data primer yang di olah (2018)

Berdasarkan Tabel 6. dapat diambil kesimpulan bahwa padaumumnya $60 \%$ petani Desa Setabu Kecamatan Sebatik Barat Kabupaten Nunukan memiliki luas lahan 2-4 ha, $18 \%$ petani memiliki luas lahan 5-7 ha, $14 \%$ petani memiliki luas lahan $8-10$ ha dan $8 \%$ petani yang memiliki luas lahan 11-12 ha.

Hak Kepemilikan berdasarkan PerundangUndangan.

Dalam UUD 1945 pasal 33 ayat (3) menyatakan: bumi, air, serta kekayaan alam yang terkandung di dalamnya dikuasai oleh Negara dan digunakan sebesar-besarnya untuk kemakmuran Rakyat. Makna yang terkandung dalam pasal tersebut 
adalah: (1), Negara menguasai bumi, air dan kekayaan alam yang terkandung di dalamnya. (2), Bumi, air dan kekayaan alam yang terkandung didalmnya di pergunakan sebesarbesarnya untuk kemakmuran rakyat. (3), tanah memiliki arti yang strategis bagi kehidupan bangsa karna tanah merupakan cabang produksi Negara yang menguasai hajat hidup orang banyak.

Sebagai wujud nyata dari pasal 33 ayat (3) Undang Undang Dasar 1945, maka lahirlah undang undang No.5 tahun 1960 tentang Peraturan Dasar Pokok-Pokok Agraria yang lebih dikenal dengan Undang Undang Pokok Agraria. Dalam undang undang pokok agraria, pengertian akan hak milik seperti yang di rumuskan di dalam Pasal 20 UUPA yang di sebutkan dalam ayat (1), hak milik adalah hak turun temurun, terkuat dan terpenuhi yang dapat di punyai orang atas tanah. (2), hak milik dapat beralih dan di alihkan kepada pihak lain.

Bilamana pengkajian dilanjutkan pada isi peraturan perundangan dibawah UndangUndang, yaitu Peraturan Pemerintah (PP) dapat dilihat bukti hak atas tanah yang mana sertifikat menjadi bukti hak atas tanah. Peraturan pemerintah No.24 Tahun 1997 tentang Pendaftaran Tanah pasal 4 ayat (1), pasal 3 huruf a, sertifikat hak ats tanah adalah bukti kepemilikan seseorang atas suatu tanah beserta bangunannya. Sertifikat hak atas tanah berguna sebagai alat bukti kepemilikan suatu hak atas tanah bagi pemegang hak atas tanah yang bersangkutan, lebih lanjut dikatakan dalam pasal (32) PP Pendaftaran Tanah bahwa sertifikat hak atas tanah merupakan surat tanda bukti hak yang berlaku sebagai alat pembuktian yang kuat mengenai data fisik dan data yuridis yang termuat didalamnya. Selanjutnya pengkajian di lakukan terhadap peraturan-peraturan mengenai hak kepemilikan atas tanah dan hal-hal yang terkait Ditemukan Peraturan Pemerintan, Keputusan Presiden, Peraturan Menteri Agraria Dan Tata Ruang / Kepala Badan Pertanahan Nasional, Peraturan Menteri Pertanian yang di dalamnya mengatur hak kepemilikan atas tanah.

Berdasarkan peraturan perundang undangan dapat dinyatakan bahwa hak pemilikan perkebunan berdasarkan Peraturan Perundang Undangan dapat berupa: 1) Hak Milik. 2) Hak Guna Usaha. 3) Hak Pakai. 4) Hak Ulayat. Adapun hak milik dapat dibuktikan dengan sertifikat sebagai alat bukti kepemilikan suatu hak atas tanah yang bersangkutan.
Fakta Hak Kepemilikan Lahan Perkebunan Kelapa Sawit

Daripenelitian yang peneliti lakukan diperoleh fakta bahwa di Desa Setabu dan Liang Bunyu Kecamatan Sebatik Barat Kabupaten Nunukan, umumnya memperoleh lahan dengan cara buka lahan sendiri, hasil beli lahandan warisan.Dilihat dari hasil penelitian bahwa fakta Hak Kepemilikan Lahan yang ada di Kecamatan Sebatik Barat, Desa setabu dan Desa Liang Bunyu Menyatakan Bahwa di Desa tersebut memiliki permasalahan namun permasalahan yang dihadapi petani kelapa sawit bisa teratasi dengan sistem kekeluargaan,Masalah yang sering terjadi di Desa Setabu dan Desa Liang Bunyu dalam lahan yaitu batas tanah/lahan sering terjadi antar lahan petani. Dari hasil wawancara yang peneliti lakukan, diketahui bahwa permasalahan tersebut terjadi akibat petani sering memindahkan batas patok lahan ke lahan/tanah lainnya yang menyebabkan terjadinya perselisiahan batas tanah/lahan'

Fakta status kepemilikan lahan di Desa Setabu dan Desa Liang Bunyu terbanyak adalah surat kepala desa yang di terbitkan nya SPPT sebanyak $36 \%$ dengan jumlah 36 orang di Desa Setabu dan di Desa Liang Bunyu 31\% dengan jumlah 31 orang,selanjutnya status kepemilikan lahan yang ada di Desa Setabu selanjutnya dengan keterangan surat dari kantor Camat (SPPH) dengan persentase $5 \%$ dengan jumlah 5 orang, dan Sertipikat dengan persentase 9\% dengan jumlah 9 orang.dan status kepemilikan lahan yang ada di Desa Liang Bunyu selanjutnya dengan keterangan surat dari kantor Camat (SPPH) dengan persentase 7\% dengan jumlah 7 orang, dan Sertipikat dengan persentase 12\% dengan jumlah 12 orang. Dapat dilihat dan disimpulkan oleh peneliti bahwa di Desa Setabu dan Liang Bunyu mengapa banyak masyarakat lebih banyak hanya mempunyai surat Desa (SPPT) itu di karenakan masyarakat disana kurang sosialisasi oleh badan pertanahan, masyarakat yang mempunyai surat Camat (SPPH) pun itu bergerak sendiri agar bisa mendapatkan Surat tersebut, dan masyarakat yang memiliki sertipikat pun itu hanya karena mereka membeli lahan yang sudah mempunyai sertipikat tanah.

\section{Kesesuaian hak pemilikan berdasarkan Perundangan dengan fakta dilapangan.}

Pada tabel 7. dapat dilihat hak kepemilikan berdasarkan Peraturan perundang-undangan terdiri atas: (1).Hak Milik; (2). HGU; (3). Hak Pakai; (4). Hak Ulayat. Hak kepemilikan 
perkebunan kelapa sawit berdasarkan fakta sebagai berikut : (1) Hak Milik (Sertipikat); (2) Alas Hak (SPPT); (3) Alas hak (SPPH). Munculnya kesesuaian antara Peraturan Perundang-undangan dengan fakta terdapat Hak Milik. Sehingga dapat dinyatakan dalam UU dan Peraturan Pemerintah bahwa hak milik berupa sertipikat dan kenyataan di Desa Setabu dan Desa Liang Bunyu sesuai.

Tabel 7. Kesesuaian hak pemilikan berdasarkan Peraturan Perundang-Undangan dengan fakta

\begin{tabular}{lll}
\hline No & $\begin{array}{l}\text { Hak-hak } \\
\text { kepemilikan } \\
\text { berdasarkan } \\
\text { peraturan } \\
\text { perundang- } \\
\text { undangan terdiri } \\
\text { sebagai berikut: }\end{array}$ & $\begin{array}{l}\text { Hak kepemilikan } \\
\text { berdasarkan } \\
\text { fakta terdiri } \\
\text { sebagai berikut : }\end{array}$ \\
\hline 1 & Hak Milik & $\begin{array}{l}\text { Hak milik } \\
\text { (SERTIPIKAT, }\end{array}$ \\
& SPPH, SPPT) \\
2 & HGU & \\
3 & Hak ulayat & \\
4 & Hak Pakai & \\
\hline
\end{tabular}

Implikasi dari hasil penelitian ini yaitu perlu adanya kebijakan percepatan sertifikasi lahan perkebunan kelapa sawit di Desa Setabu dan Desa Liang Bunyu Kecamatan Sebatik Barat. Yang diatur dalam Peraturan Kepala Badan Nasional Nomor 35 tahun 2016 tentang percepatan Pelaksanaan Pendaftaran Sistematis lengkap di wilayah Republik Indonesia dalam rangka memberikan jaminan kepastian hukum dan perlindungan hak atas tanah rakyat secara adil, serta mendorong pertumbuhan ekonomi.

\section{KESIMPULAN}

Berdasarkan hasil penelitian maka dapat di ambil kesimpulan sebagai berikut :

1.Hak Kepemilikan Lahan Berdasarkan Peraturan Perundangan

1)Hak milik adalah hak turun temurun, terkuat dan terpenuh yang dapat dipunyai orang atas tanahdengan mengingat ketentuan Pasal 6.

2)Hak Kepemilikan Tanah / Tanah Perkebunan terdiri atas

a.Hak guna usaha

b.Hak milik

c.Hak pakai

d.Hak Ulayat

3)Hak dapat diperoleh melalui Pendaftaran tanah
2.Terdapat bukti Kepemilikan lahan di Desa Setabu dan Desa Liang Bunyu berupa surat Kepala Desa (SPPT) dengan persentase 67\%, Camat (SPPH) dengan persentase $12 \%$, dan Sertipikat dengan persentase $21 \%$ yang didalamnya memiliki Kumpulan Hak terdiri atas akses, pengelolaan,eksklusi, dan pengalihan. Sama-sama memiliki hak atas akses, pengelolaan,eksklusi, dan pengalihan.

Memperhatikan hak berdasarkan peraturan perundang-undangan dan fakta dilapangan dapat disimpulkan bahwa pada prinsipnya hak kepemilikan lahan itu memiliki kesesuaian .berkesesuaian jika di tinjau dari sisi hak milik.

\section{DAFTAR PUSTAKA}

Badan Pusat Statistik. 2017. Kabupaten Nunukan dalam angka 2017. BPS Kabupaten nunukan. Kabupaten Nunukan.

Harsono,Boedi, 2008, Hukum Agraria Indonesia: Sejarah Pembentukan Undang-Undang Pokok Agraria, Isi Dan Pelaksanaannya, Djambatan, Jakarta.

Harsono, 2010, Hukum Agraria Indonesia: Sejarah Pembentukan Undang-Undang Pokok Agraria, Isi Dan Pelaksanaannya, Djambatan, Jakarta.

Peraturan Kepala BPN/Menteri Negara Agraria Nomor 3 Tahun 1997 Tentang Pelaksanaan PP Nomor 24 / 1997.

Peraturan Menteri Dalam Negeri Nomor 6 Tahun 1972 Tentang Pelimpahan Wewenang Pemberian Hak Atas Tanah.

Peraturan Menteri Pertanian Republik Indonesia Nomor 98/Permentan/ot.140/9/2013 Tentang Pedoman Perizinan Usaha Perkebunan.

Peraturan Pemerintah No. 10 Tahun 1961 tentang Pendaftaran Tanah, Jakarta.

Peraturan Pemerintah Nomor 24 Tahun 1997 tentang Pendaftaran Tanah.

Peraturan Pemerintah Nomor 24 Tahun 1997 Tentang Pendaftaran Tanah

Peraturan Pemerintah Nomor 38 Tahun 1963 Tentang Penunjukan Badan-Badan Hukum Yang dapat Mempunyai Hak Milik atas Tanah.

Peraturan Pemerintah Nomor 40 Tahun 1996 Tentang Hak Guna Usaha, Hak Guna Bangunan dan Hak Pakai.

Sutrisno Adi. 2012. Analisis Persepsi dan Motivasi Petani Terhadap Manfaat Sumberdaya Hutan Lindung Pulau Tarakan. Institut Pertanian Bogor

Peraturan Kepala BPN/Menteri Negara Agraria Nomor 3 Tahun 1997 Tentang Pelaksanaan PP Nomor 24 / 1997.

Peraturan Menteri Pertanian Republik Indonesia Nomor 98/Permentan/ot.140/9/2013 Tentang Pedoman Perizinan Usaha Perkebunan.

Peraturan Pemerintah Nomor 24 Tahun 1997 tentang Pendaftaran Tanah.

Undang-Undang Nomor 5 Tahun 1960 Tentang Peraturan Pokok-Pokok Agraria. 
Undang-Undang No. 56/Prp/1960, Penetapan Luas Tanah Pertanian.

Undang-Undang Nomor 39 Tahun 2014 Tentang Perkebunan. 